\title{
Retrieval of characteristic parameters for water vapour transmittance in the development of ground-based sun-sky radiometric measurements of columnar water vapour
}

\author{
M. Campanelli ${ }^{1}$, T. Nakajima ${ }^{2}$, P. Khatri ${ }^{3}$, T. Takamura ${ }^{3}$, A. Uchiyama ${ }^{5}$, V. Estelles $^{4}$, G. L. Liberti ${ }^{1}$, and \\ V. Malvestuto ${ }^{1,}$ \\ ${ }^{1}$ Consiglio Nazionale delle Ricerche (CNR), Institute of Atmospheric Sciences and Climate (ISAC), Rome, Italy \\ ${ }^{2}$ Center for Climate System Research (CCSR), The University of Tokyo, Kashiwa, Japan \\ ${ }^{3}$ Center for Environmental Remote Sensing (CEReS), Chiba University, CHIBA, Japan \\ ${ }^{4}$ Dept. Fisica de la Terra y Termodinamica, Facultat de Fisica, Burjassot (Valencia), Spain \\ ${ }^{5}$ Meteorological Research Institute, Tsukuba-city, Japan \\ 'deceased, May 2011
}

Correspondence to: M. Campanelli (m.campanelli@isac.cnr.it)

Received: 14 May 2013 - Published in Atmos. Meas. Tech. Discuss.: 3 September 2013

Revised: 29 January 2014 - Accepted: 13 March 2014 - Published: 29 April 2014

\begin{abstract}
Sun-sky radiometers are instruments created for aerosol study, but they can measure in the water vapour absorption band allowing the estimation of columnar water vapour in clear sky simultaneously with aerosol characteristics, with high temporal resolution. A new methodology is presented for estimating calibration parameters (i.e. characteristic parameters of the atmospheric transmittance and solar calibration constant) directly from the sun-sky radiometer measurements. The methodology is based on the hypothesis that characteristic parameters of the atmospheric transmittance are dependent on vertical profiles of pressure, temperature and moisture occurring at each site of measurement. To obtain the parameters from the proposed methodology some seasonal independent measurements of columnar water vapour taken over a large range of solar zenith angle simultaneously with the sun-sky radiometer measurements, are needed. In this work high time resolution columnar water vapour measurements by GPS were used as independent data set, but also the case when such measurements are not available was considered by developing the surface humidity method (SHM). This methodology makes it possible to retrieve the needed independent data set of columnar water vapour using the standard surface meteorological observations (temperature, pressure and relative humidity) more readily available. The time pattern of columnar
\end{abstract}

water vapour from sun-sky radiometer retrieved using both the methodologies was compared with simultaneous measurements from microwave radiometer, radiosondings and GPS. Water vapour from sun-sky radiometer, obtained using GPS independent measurements, was characterized by an error varying from $1 \%$ up to $5 \%$, whereas water vapour from SHM showed an error from $1 \%$ up to $11 \%$, depending on the local columnar water occurring at the site during the year. These errors were estimated by comparing water vapour series from sun-sky radiometer against measurements taken by GPS at a nearby station. The accordance between retrievals from sun-sky radiometer and simultaneous measurements from the other instruments was found always within the error both in the case of SHM and of the GPS independent data set.

Water vapour obtained using characteristic parameters of the atmospheric transmittance dependent on water vapour was also compared against GPS retrievals, showing a clear improvement with respect to the case when these parameters are kept fixed. 


\section{Introduction}

Water vapour columnar content is an important parameter to be estimated since it is a greenhouse component affecting the earth's climate. Many techniques have been developed for measuring the water vapour amount - from satellite remote sensing, in the visible, infrared or microwave spectral regions, from ground based remote sensing, i.e. GPS, sunphotometers, microwave radiometers, or from radiosondings. Sun-sky radiometers are instruments designed for aerosol study, and many of them can also measure in the water vapour absorption band, allowing estimation of the columnar water vapour in clear sky condition, simultaneously with aerosol characteristics, with high temporal resolution up to a few minutes. Despite the limits of the sunphotometry technique related to clear sky daytime conditions, the high temporal sampling and the wide distribution of these instruments all over the world make the development of methodologies for retrieving columnar water from sun-sky radiometers of great interest. The most important problem in using these instruments is the estimation of the solar calibration constant and of the $a$ and $b$ parameters characterizing the atmospheric transmittance in the water vapour band: $T=\mathrm{e}^{-a(m W)^{b}}$ (Bruegge et al., 1992), where $m$ is the optical air mass and $W$ is the columnar water vapour content. Some methods for estimation of $W$ from sun-sky radiometers have already been developed (Halthore et al., 1997; Alexandrov et al., 2009; Schmid et al., 2001). They are mainly based on the combined use of a radiative transfer code to determine the $a$ and $b$ parameters and of Langley plot techniques for estimation of the solar calibration constant. Within the AERONET sun-sky radiometer network (Holben et al., 1998) a methodology for estimating $W$ from the solar irradiance measured at wavelength of $940 \mathrm{~nm}$ has already been implemented. The algorithm of Holben et al. is based on a use of a radiative transfer code (Smirnov et al., 2004) for computing $T$ as a function of $W$ and then estimating $a$ and $b$ parameters from a curve-fitting procedure. The solar calibration constant is determined by a modified Langley plot calibration performed at Mauna Loa Observatory (3400 m a.s.1). The uncertainty of its retrieval was found to be 10 times greater than for the other wavelengths in the visible region, varying from $3 \%$ to $5 \%$ (T. Eck, personal communication, 2009). A problem connected with these methodologies is that only one pair of $(a, b)$ parameters is used for each kind of $940 \mathrm{~nm}$ interference filter, neglecting the dependence of $T$ on the vertical profile of temperature, pressure and moisture at the various sites. This method is convenient for a network consisting of several instruments, but its accuracy needs more investigation.

Campanelli et al. (2010) presented a new methodology for estimating $a$ and $b$ parameters directly from the measurements themselves, not relying on any radiative transfer calculation and therefore reducing simulation errors and potentially containing information on seasonal changes in vertical profiles of temperature, air pressure and moisture occurring at each measurement site. To retrieve the calibration constants from the proposed methodology some seasonal independent measurements of $W$ (such those by radiosondes, microwave radiometers or GPS receivers) taken over a large range of solar zenith angle simultaneously with the sun-sky radiometer measurements are needed. In the previous paper (Campanelli et al., 2010) data of radiosondes were used for retrieving calibration constants only in summer, but times when such independent measurements are not available were also considered. For the latter cases, the surface humidity method (SHM) was developed, allowing the application of the procedure using $W$ estimated by only measurements of surface temperature, pressure and relative humidity.

In the present paper we will improve and elaborate on several points left open in the previous paper: the study of $a, b$ variation as a function of columnar water vapour amount by applying the methodology to an entire year data set; the estimation of $a$ and $b$ retrieval errors using a Monte Carlo method; the development of a preliminary check on the quality of both sun-sky radiometer and the independent water vapour data sets; the retrieval of calibration constants using, as independent data set, the high temporal resolution water vapour measurements from GPS receivers; the validation of the SHM examining in detail the accuracy, problems and utility of this methodology. Results will be compared against measurements taken by a microwave radiometer, radiosondes and GPS receivers.

\section{Equipment}

The present methodology was applied to measurements performed during 2007 at the Chiba University $\left(140.124^{\circ} \mathrm{E}\right.$ $35.622^{\circ} \mathrm{N}, 34 \mathrm{~km}$ SE from Tokyo, Fig. 1) by the Center for Environmental Remote Sensing, Chiba University, Japan. A PREDE sun-sky radiometer model POM 02, part of the Skynet network (Takamura and Nakajima, 2004; http:// atmos.cr.chiba-u.ac.jp/), was used. This instrument is a scanning spectral radiometer taking measurements of solar direct and diffuse irradiance every $5 \mathrm{~min}$ at several wavelengths in the visible and near-infrared regions $(340 \mathrm{~nm}, 380 \mathrm{~nm}$, $400 \mathrm{~nm}, 500 \mathrm{~nm}, 870 \mathrm{~nm}, 940 \mathrm{~nm}, 1020 \mathrm{~nm}$ ) appropriately chosen for aerosol study and therefore clear from gas absorption. Measurements of direct solar irradiance taken at $940 \mathrm{~nm}$ are used for estimating the columnar water vapour content in clear sky conditions. Ancillary co-located measurements of pressure and relative humidity, needed for the application of the SHM, were provided by the Japan Meteorological Agency.

Columnar water vapour estimation from two GPS receiver stations (Shoji, 2013), provided by the Meteorological Research Institute of Ibaraki, Japan, were considered: no. 950225 (called GPS1 from now on) located at ChibaHanamigawa $\left(140.048^{\circ} \mathrm{E}, 35.657^{\circ} \mathrm{N}\right.$, alt. $\left.8.284 \mathrm{~m}\right)$ about 


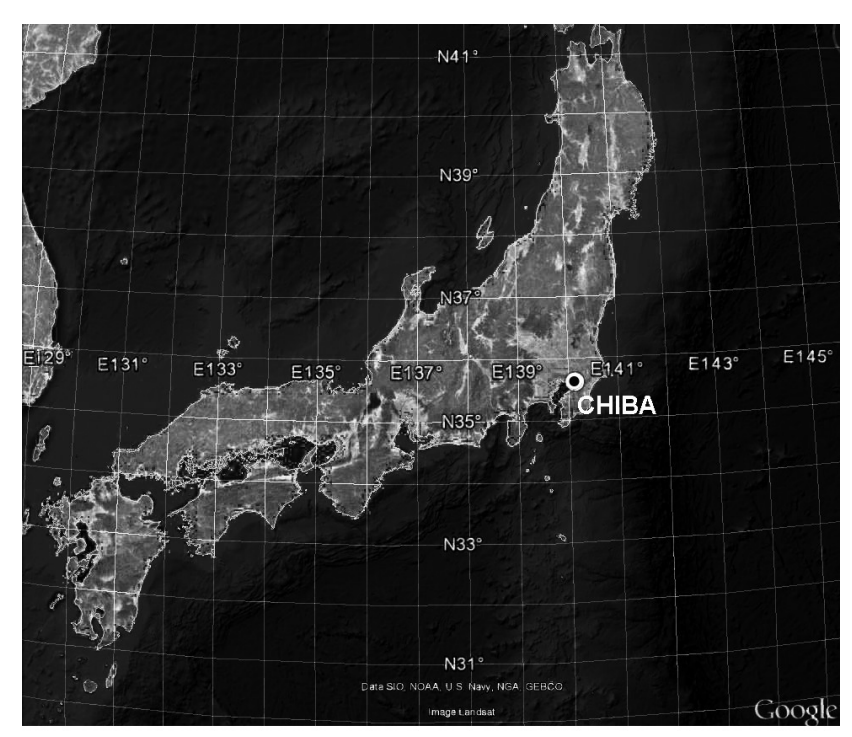

Fig. 1. Geographical position of the Chiba station in Japan.

$19 \mathrm{~km} \mathrm{~W}$ from Chiba University, and no. 93025 (called GPS2 from now on) located in Chiba-Midori $\left(140.186^{\circ} \mathrm{E}\right.$, $35.544^{\circ} \mathrm{N}$, alt: $50.346 \mathrm{~m}$ ) about $10 \mathrm{~km} \mathrm{SW}$ from Chiba University.

Measurements taken from a microwave radiometer (MWR) and from radiosondings (RDS) were also considered. The former (co-located with the above-mentioned instruments) is a Radiometrix WVR-1100 portable water vapour passive radiometer measuring microwave radiation from the sky at $23.8 \mathrm{GHz}$ and $31.4 \mathrm{GHz}$. These two frequencies allow the simultaneous determination of integrated liquid water and integrated water vapour along a selected path. In the case of water vapour and liquid water, the atmosphere is rather translucent in the vicinity of the $22.2 \mathrm{GHz}$ water vapour resonance line, and total integrated water, water vapour and phase path delay can be derived thanks to their linear dependence on the atmospheric opacity at the measuring wavelengths. The coefficients of these linear equations are determined from the bilinear regression of water vapour and inferred liquid water data derived from radiosonde observations.

Radiosonde measurements were extracted from the Integrated Global Radiosonde Archive (IGRA, http://www.ncdc. noaa.gov/oa/climate/igra/) which contains quality controlled radiosonde and pilot balloon observations from over 1500 globally distributed stations (Durre et al., 2006). The station closest to Chiba is Tateno $\left(140.13^{\circ} \mathrm{E}, 36.05^{\circ} \mathrm{N}\right)$, in the prefecture of Ibaraki about $46 \mathrm{~km} \mathrm{~N}$ from Chiba. The information and sampling of the radiosondings contained in the IGRA archive are, in the majority of the cases, the ones originally sent to the Global Telecommunication System (GTS) of the World Meteorological Organization (WMO). The reported variables, in the IGRA data set, are pressure $(\mathrm{Pa})$, geopotential height $(\mathrm{m})$, air temperature $\left({ }^{\circ} \mathrm{C}\right)$, dew point depression (DPD) $\left({ }^{\circ} \mathrm{C}\right)$, wind direction $\left({ }^{\circ}\right)$ and speed $\left(\mathrm{m} \mathrm{s}^{-1}\right)$. Air temperature and DPD are reported with a $0.1^{\circ} \mathrm{C}$ numerical discretization. Quality assurance flags are given for each pressure, geopotential height and temperature value, indicating whether the corresponding value was checked by procedures based on climatological means and standard deviations. Concerning the vertical sampling in the reported profile, in accordance with WMO guidance, radiosondes should report standard pressure levels $(1000,925,850,700,500$, 400, 300, 250, 200, 150, 100, 70, 50, and $10 \mathrm{hPa}$ ), surface, tropopause and significant thermodynamic and wind levels (WMO, 1986, 1995). Radiosonde estimates of the total precipitable water vapour are obtained by computing the specific humidity for each level, having valid temperature, pressure and DPD measurements, and then integrating numerically the specific humidity over the vertical using a pressureweighted numerical integration scheme.

\section{Methodology}

The direct solar irradiance measurement $V(\mathrm{~mA})$ taken by the sun-sky radiometer at the $940 \mathrm{~nm}$ wavelength in clear sky condition is related to the solar calibration constant $V_{0}$ (extra-terrestrial current $\mathrm{mA}$ ) at the same wavelength through the following expression:

$V=V_{0} \mathrm{e}^{-m\left(\tau_{\mathrm{a}}+\tau_{\mathrm{R}}\right)} \mathrm{e}^{-a(m W)^{b}}$,

where (i) $m$ is the relative optical air mass (Kasten and Young, 1989) function of the solar zenith angle, (ii) $\tau_{\mathrm{a}}$ and $\tau_{\mathrm{R}}$ are the aerosol extinction optical thicknesses and molecular Rayleigh scattering at $940 \mathrm{~nm}$, respectively, and (iii) $T=\mathrm{e}^{-a(m W)^{b}}$ is the water vapour partial atmospheric transmittance at $940 \mathrm{~nm}$ as a function of $m$ and $W$, with $a$ and $b$ constants (Bruegge et al., 1992). Once $a$ and $b$ have been determined, $V_{0}$ can be estimated, and $W$ can subsequently be calculated.

Equation (1) can be also written in the form

$y=\ln V_{0}-a x$,

with $\left\{\begin{array}{l}y=\ln V+m\left(\tau_{a}+\tau_{R}\right) \\ x=(m W)^{b} .\end{array}\right.$

The aerosol optical thickness $\tau_{\mathrm{a}}$ is estimated at wavelength $\lambda=940 \mathrm{~nm}$, according to the well-known Ångström formula

$\tau_{\mathrm{a}}(\lambda)=\beta \lambda^{-\alpha}$,

where wavelength $\lambda$ is measured in $\mu \mathrm{m}, \alpha$ is the so-called Angström exponent, and $\beta$ is the atmospheric turbidity parameter. Parameters $\alpha$ and $\beta$ are determined by the regression from Eq. (3) where the spectral series of $\tau_{\mathrm{a}}$ are retrieved by 
the sun-sky radiometer measurements taken at the other visible and near-infrared wavelengths 400, 500, 675, 870, and $1020 \mathrm{~nm}$.

In order to find the most appropriate pair of values $(a, b)$, the following steps are performed: (i) from Eq. (2b) $x$ values are calculated for 30 different values of $b$ from 0.4 to 0.7 with a step of 0.01 and each time the $(x, y)$ squared correlation coefficient is calculated; then the maximization of the $(x, y)$ squared correlation coefficient is used to determine the best exponent $b$; (ii) once the optimal $b$ exponent is retrieved, the series of $x$ values is computed and used in Eq. (2a) where the regression line of $y$ versus $x$ allows the retrieval of the coefficients $a$ and $V_{0}$. This modified version of the Langley plot (called " type-2 modified Langley") is different from the other modified Langley methods described by Halthore et al. (1997) and Schmid et al. (2001) (called " type-1 modified Langley"). In fact whereas the latter determines $V_{0}$ as the intercept of the straight line obtained by fitting $y$ versus the power term $m^{b}$, in the former $V_{0}$ is retrieved by plotting $y$ versus the product $a x$ where $x=(m W)^{b}$. This approach largely improves the application of the Langley methods to cases where the time patterns of $W$ is not stable. In fact the " type-1 modified Langley" assumes that $y$ only depends on air mass, $m$, and that all points have the same $W$. When a variability of $W$ is recorded, the neglected dependence of $y$ on $W$ causes a scatter of the points and introduces calibration errors and large day-to-day changes in the retrieved calibration constants. Conversely "type- 2 modified Langley" gives evidence to the dependence of $y$ on $(m W)$ and the variability of $y$ is explained by the real variability of the product $(m W)$, providing a better retrieval of the intercept $\left(\ln V_{0}\right)$ also when the time pattern of precipitable water content is not stable. In Fig. 2 type- 1 and type-2 Langley plot methods were used to retrieve $V_{0}$ in two cases: stable (13 June 2007) and unstable (12 June 2007) time patterns of $W$ as measured at Chiba by the microwave radiometer simultaneously to the sun-sky radiometer. It is clear that using the type- 2 method, the points are less scattered especially in the case of a more unstable $W$ time pattern. In Table 1 the retrieved $V_{0}$ values are shown. The absolute difference between the $V_{0}$ values retrieved by the two methods from 12 to 13 June is only $1.8 \%$ if type2 is used, whereas it increases up to $4.1 \%$ when type- 1 is adopted, highlighting the better capability of type- 2 in estimating $V_{0}$ during both stable and unstable $W$ time periods.

Once parameters $V_{0}, a$ and $b$ have been determined, the values of precipitable water vapour content $W_{P}$ can be calculated according to the equation

$W_{P}=\frac{1}{m} \cdot\left[\frac{1}{a} \cdot\left(\ln V_{0}-y\right)\right]^{\frac{1}{b}}$.

With respect to the previous version published in Campanelli et al. (2010), the procedure has been improved in two main respects: the use of a Monte Carlo method for the evaluation of errors affecting the $a$ and $b$ retrievals, and the study of their variation as a function of columnar water vapour amount by applying the methodology to a data set for an entire year. Concerning the first aspect, the improvement consists of the following.

1. A preliminary check on the quality of both sun-sky radiometer and the independent water vapour data sets (as described in Sect. 4) performed before the application of the methodology.

2. After the optimal values of $a$ and $b$ are found, the residual standard deviation $\sigma_{\text {RES }}$ is computed around the optimal regression line.

3. A Monte Carlo approach is used to simulate 80 fictitious bivariate samples of the pair of variables $x_{1}=$ $m \cdot W$ and $y$, each fictitious sample sharing with the true sample:

i. the number $N$ of data available

ii. the lower and upper bounds of $x_{1}$

iii. the noise around the ideal straight line.

More precisely, the $x_{1}$ data are generated by sorting $N$ random values uniformly distributed between $x_{1 \mathrm{MIN}}$ and $x_{1 \mathrm{MAX}}$, while the $y$ data are generated by the formula: $y=\ln V_{0}-$ $a x_{1}^{b}+$ noise, where the $a$ and $b$ (and then $\left.\ln \left(V_{0}\right)\right)$ values are the optimal values retrieved above for the given real sample, while the noise is a Gaussian noise with standard deviation coincident with $\sigma_{\text {RES }}$. Then for each of the 80 fictitious samples a search of the optimal $a$ and $b$ values is carried out using the same procedure followed to find the actual optimal values (i.e. by maximizing the determination coefficient $R^{2}$ of the regression line). In this way, a list of 80 pairs $(a, b)$ are retrieved. For each of these parameters it is then possible to evaluate both the mean and the standard deviation. The coincidence of the two means $\bar{a}$ and $\bar{b}$ with their respective ideal values is a test for the goodness of the optimization procedure. This coincidence has been successfully verified in all our Monte Carlo simulations. Given that, the standard deviation (that is the uncertainty associated with the above mean values) appears to be the best estimate of standard error to associate with each of the actual optimal values $a_{\text {opt }}, b_{\text {opt }}$, and therefore the best estimate of the uncertainty associated with the entire procedure. This evaluation is an improvement with respect to the estimation obtained using a simple propagation error formula.

4. Optimal $V_{0}$ is calculated by the linear fit of Eq. (2a) using the pair $a_{\mathrm{opt}}, b_{\mathrm{opt}}$. The error affecting $V_{0}$ is obtained by evaluating the standard error on the regression line intercept $\left(\ln \left(V_{0}\right)\right)$ and then applying a simple propagation error formula.

Regarding the second improvement, namely the study of $a, b$ variation as a function of columnar water vapour amount, it 

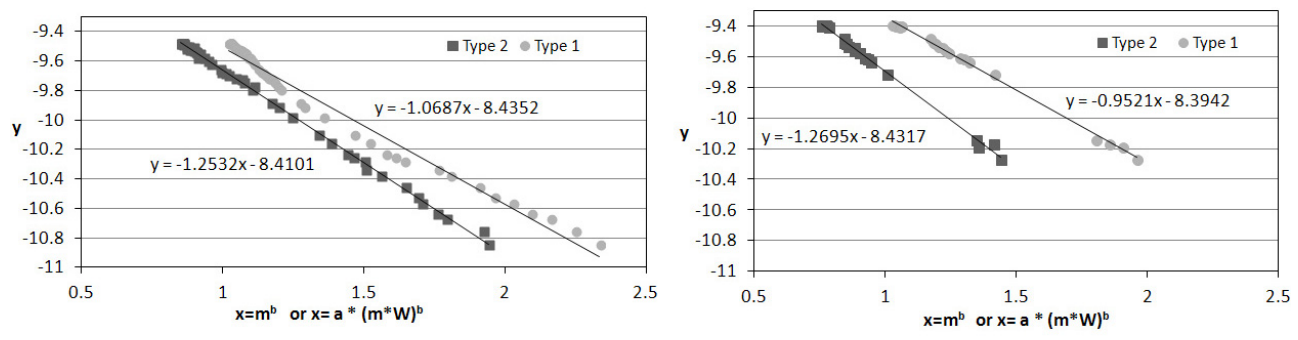

12 June 2007
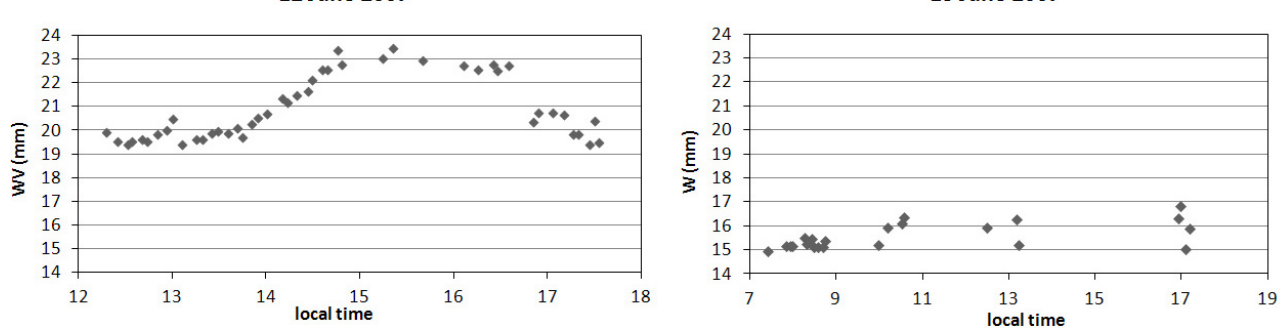

Fig. 2. Water vapour time pattern and application of type-1 and type-2 modified Langley methods for stable (right) and unstable (left) water vapour time pattern cases. A fixed indicative value of $b=0.6$ (as suggested by Halthore et al., 1997, for narrow band filters) has been assumed.

Table 1. Retrieval of $V_{0}$ for stable and unstable water vapour time pattern cases, using type-1 and type- 2 modified Langley methods.

\begin{tabular}{lrrr}
\hline$V_{0}$ & 12 June & 13 June & $\%$ Diff \\
\hline type-1 & $2.17 \times 10^{-4}$ & $2.28 \times 10^{-4}$ & $4.1 \%$ \\
type-2 & $2.23 \times 10^{-4}$ & $2.19 \times 10^{-4}$ & $-1.8 \%$ \\
\hline
\end{tabular}

is evident that since $a, b$ are supposed to depend on vertical profiles of temperature, air pressure and moisture their "seasonal" estimation is incorrect, since seasons are only a rough subdivision of the year, marked by changes in weather, measurement environment and hours of daylight. Therefore $a, b$ were provided for several water vapour classes and their number their thresholds will be described in Sect. 4.

\section{Preliminary check of data set}

Simultaneous measurements of sun-sky radiometer $V$ and independent data set $W$ were selected for the application of Eq. (2a) and (2b). All the estimations of $W$ within 15 min before and after measurements of signal $V$ were taken, and all the values of $\tau_{A}$ and $\tau_{R}$ within the same intervals were selected and averaged over 30 min time intervals. The present method was applied in the range of solar elevation angle yielding $m<8$.

A preliminary check on the quality of each data set was performed as follows.

1. Data corresponding to $\tau_{\mathrm{a}}(940 \mathrm{~nm})>0.4$ are rejected.

In the present study the cloud screening is performed by selecting only measurements whose RMS deviation between measured and reconstructed diffuse sky irradiance, in the wavelengths devoted to aerosol study, is lower than $8 \%$. This criterion assured the rejection of cloud-contaminated direct and diffuse irradiance measurements, but it could not exclude the contamination of high and thin cirrus clouds. With the maximum average value of $\tau_{\mathrm{a}}(500 \mathrm{~nm})$ being about 0.6 , and considering the corresponding values of the Angstrom exponent, it is likely that data having $\tau_{\mathrm{a}}(940 \mathrm{~nm})>0.4$ are contaminated by clouds, and for this reason they must be rejected, even if some good data will probably be lost.

2. Data taken before 13:00 local time from October to May were rejected.

During these months the behaviour of $y$ vs. $x$ appears very often not linear, as shown in Fig. 3. In these cases two separate behaviours can be recognized: generally one in the morning and one in the afternoon. This is likely related to the fact that in these months and at this time of day (conversely to the summer season) more time is needed to break the stable conditions characterizing the low atmosphere after the nocturnal cooling period. As a consequence, the vertical distribution of water vapour is anomalous with respect to the profiles generally used in the development and/or initialization of retrieval methods (e.g. microwave radiometer, GPS, SHM) and an error can be introduced in the estimation of $W$. For these months we decided, as a first approximation, to select only measurements initiating from 13:00 local time in order to reduce the problem to a linear behaviour.

3. A statistical selection was applied to discard outliers with deviation greater than $2 \sigma$ from the regression line. 


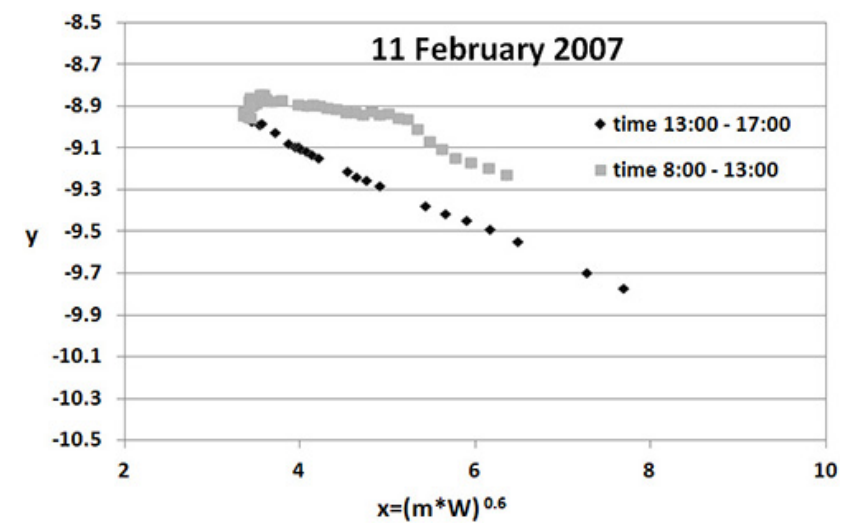

Fig. 3. Example of the application of type-2 modified Langley plot during winter time. The $x$ value is calculated for a fixed indicative $b=0.6$ (as suggested by Halthore et al., 1997, for narrow band filters).

\section{Parameter estimation}

Because $a$ and $b$ are supposed to depend on the vertical distribution of the columnar water vapour and then on its total amount: (i) the entire yearly independent $W$ data set was divided in four classes: [0-10] mm; [10-20] $\mathrm{mm}$; [20-40] mm; [>40] $\mathrm{mm}$; an overlap between classes of $\pm 1 \mathrm{~mm}$ was considered for the thresholds of each class; (ii) the procedure was applied for each class with the aim of providing water vapour dependent $a$ and $b$. The choice of a larger interval for the third class is strictly related to the need of having a sufficiently large number of data points in the data set, comparable to or greater than the other three classes.

Two different independent $W$ data sets were used for the retrieval of calibration parameters: (i) $W$ from GPS receivers, (ii) $W$ from SHM. The first choice is motivated by the consideration that GPS is able to provide the highest quality estimation of $W$, even if a small dependence on vertical profile of temperature and water vapour needs to be corrected by an empiric relation generally retrieved from the local climatology (Shoji, 2013; Ortiz et al., 2011; Bevis et al., 1992). However, it is not yet very common to find GPS estimations close to measurement sites, nor $W$ from radiosondes taken over a large range of solar zenith angle, as in our case for Tateno station, where only one radiosonde launch is performed during the daytime. In this case the SHM can be used.

MWR in Chiba and RDS in Tateno were used to validate the results.

\subsection{W from GPS as independent data set}

As already stated in Sect. 3, two stations equipped with GPS receivers are available close to Chiba University. A preliminary comparison between their results ( $\left.W_{\mathrm{GPS} 1}, W_{\mathrm{GPS} 2}\right)$ showed a difference always below $1 \%$ for all the four classes with the exception of the third class where it was found to be
$2 \%$. We decided to use $W_{\mathrm{GPS} 2}$ as independent data set for the application of the methodology, and $W_{\mathrm{GPS} 1}$ to estimate the error affecting the retrieval of water vapour from sun-sky radiometer $\left(W_{P}\right)$.

\subsection{W from SHM as independent data set}

The SHM consists in estimating the $W$ data set using surfacelevel observations of moisture parameters that are much more common than those performed with RDS or MWR. According to Hay (1970) there is a linear dependence between precipitable water content $\left(W_{\mathrm{SHM}}\right)$ and water vapour partial pressure $e_{0}[\mathrm{hPa}]$ at the surface, expressed by

$W_{\mathrm{SHM}}=c_{1} e_{0}+c_{2}$,

where the quantity $e_{0}$ is calculated as the product of the surface relative humidity $f_{0}$ and the saturation water vapour pressure $E\left(T_{0}\right)(\mathrm{hPa})$. The latter is calculated as a function of surface temperature $T_{0}(\mathrm{~K})$ according to the following Lowtran code formula (Kneizys et al., 1983):

$E\left(T_{0}\right)=\frac{A \mathrm{e}^{\left(18.9766-14.9595 A-2.4388 A^{2}\right)} 10^{-6}}{W_{\mathrm{m}} R T_{0} \times 10^{3}}$,

where $A=273.15 / T_{0}, R=8.314 \times 10^{7}$ is the gas constant $\left(\mathrm{erg} \mathrm{K}^{-1} \mathrm{~mol}^{-1}\right.$ ) and $W_{\mathrm{m}}=18.02$ is the molecular weight of water vapour $\left(\mathrm{g} \mathrm{mol}^{-1}\right)$. Estimation of coefficients $c_{1}$ and $c_{2}$ can be found in the literature, from different daily or monthly data sets and from varying numbers of measurements and sites (for example Hay, 1970; Tuller, 1977; Choudhury, 1996; Liu, 1986). $W_{\text {SHM }}$, as defined in Eq. (5), was estimated using $c_{1}$ and $c_{2}$ coefficients taken from Yamamoto et al. (1971). They retrieved an empirical formula for the relation between $W_{\mathrm{SHM}}$ and $e_{0}$ (Eq. 7) using aerological measurements taken between 1950 and 1970 at several Japanese stations, during clear sky conditions:

$W_{\mathrm{SHM}}= \begin{cases}0.14 \cdot e_{0}, & \text { for } \quad e_{0} \leq 15 \mathrm{hPa} \\ 0.18 \cdot e_{0}-0.60, & \text { for } \quad 15<e_{0} \leq 25 \mathrm{hPa} \\ 0.23 \cdot e_{0}-1.85, & \text { for } \quad e_{0}>25 \mathrm{hPa}\end{cases}$

The SHM is able to provide reliable estimation of precipitable water content when vertical humidity decreases as a function of height in a nearly exponential profile, but this assumption does not always hold. Undoubtedly an error in $W_{\text {SHM }}$ estimation can affect the validity of Eq. (2), but the precipitable water content amount by sun-photometric observations $\left(W_{P}\right)$ can be derived accurately through Eq. (4), unless $a$ and $b$ coefficients are too far from reality, as will be discussed in Sect. 6.

Calibration parameters $a, b$ and $V_{0}$ for each $W$ class retrieved using both $W_{\mathrm{GPS} 2}$ and $W_{\mathrm{SHM}}$ are shown in Fig. 4 and Table 2. In Fig. 5 plots of the type-2 modified Langley for each of the four water vapour classes, in the case of $W_{\mathrm{GPS} 2}$, are shown. 

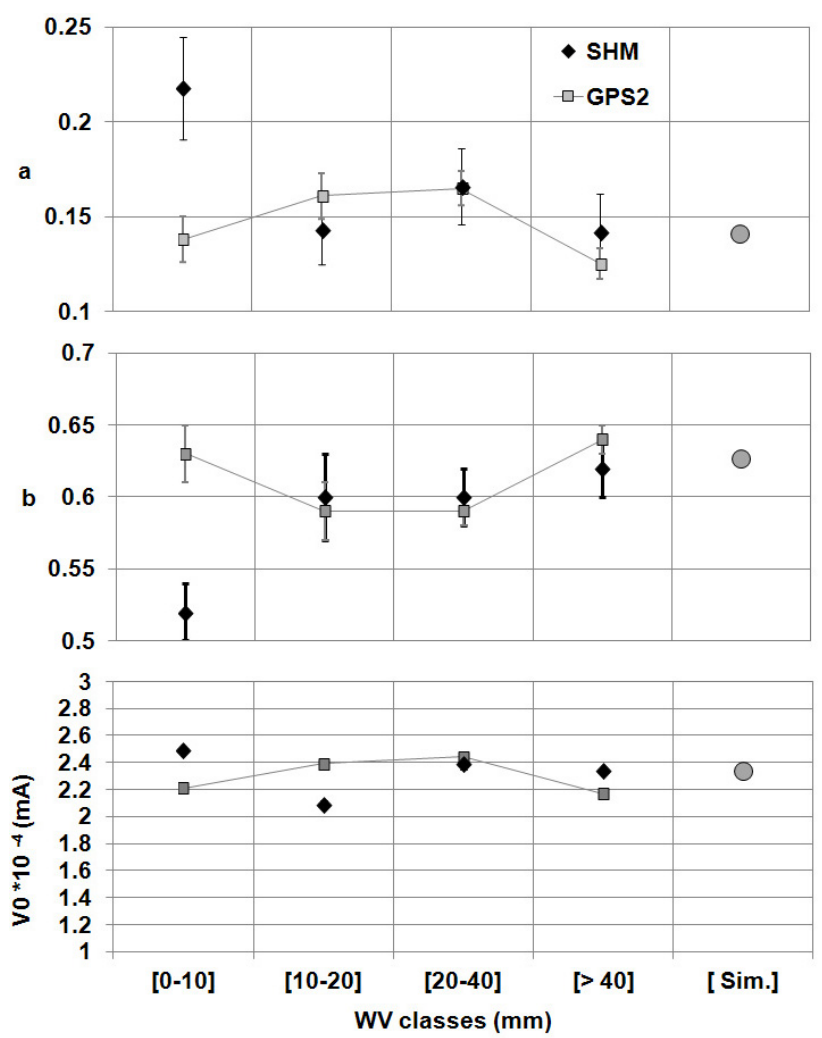

Fig. 4. Parameters $a, b$ and $V_{0}$ as estimated by the presented methodology (black points), see Table 2 . The grey circles refer to the retrieval obtained by a fitting procedure of a simulated transmittance.

As expected, the uncertainty on the determination of $a$ and $b$ parameters is greater for the case of SHM due probably to the lower accuracy of $W_{\text {SHM }}$ estimation. However, in all the classes for both use of $W_{\mathrm{GPS} 2}$ and $W_{\mathrm{SHM}}$ the uncertainty is below $3 \%$ and $5 \%$ for $b$ and below $9 \%$ and $14 \%$ for $a$.

Looking at the water vapour dependence of the $a, b$ and $V_{0}$ parameters in Fig. 4, is particularly noticeable that their behaviours are somehow connected since the increase of one parameter is balanced by the decrease of another. This is due to the fact that in the applied methodology of maximization these variables are not calculated independently of one another. This implies that the slight dependence of $V_{0}$ on the water vapour class is a fictitious tendency, and therefore, at the present stage, the retrieved $V_{0}$ should be considered as an effective calibration constant whose temporal variation could not be related to a real instrumental drift. Nevertheless, its total uncertainty (estimated as the standard deviation of the values divided by their mean) resulted to be about $6 \%$ and $7 \%$ respectively when $W_{\mathrm{GPS} 2}$ and $W_{\mathrm{SHM}}$ are used, which is slightly larger than the maximum uncertainty retrieved by AERONET at Mauna Loa Observatory ( $5 \%)$.

A comparison between the two methodologies showed a general good agreement of $a$ and $b$ values that are always
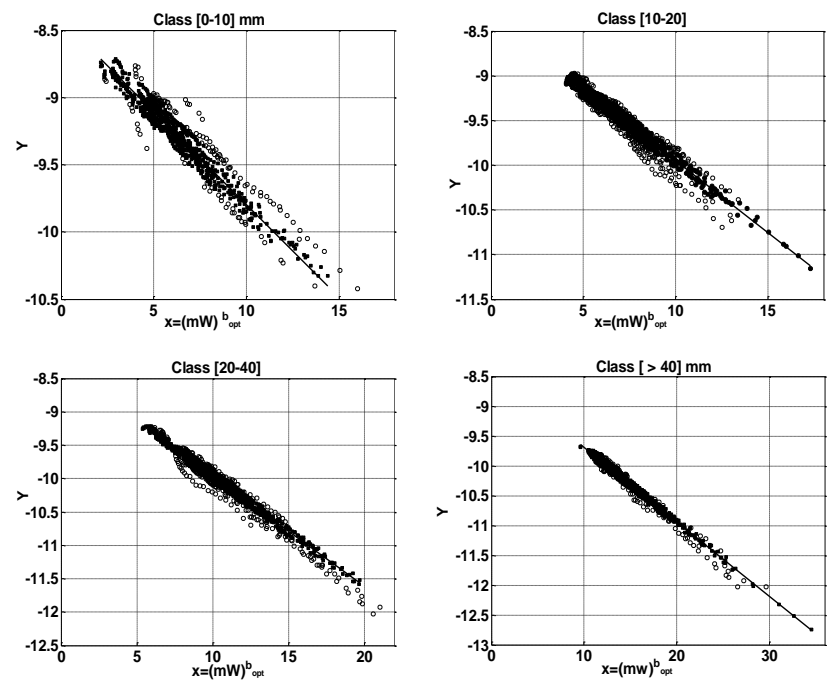

Fig. 5. Type-2 modified Langley for each of the four water vapour classes. Open circles are points discarded from the quality check selection. $W$ is from GPS2; $b$ is the retrieved optimal value for each class, see Table 2.

within the estimated error, with the exception of the first class where the SHM provides too low a value of $b$ and consequently too high a value of $a$.

The behaviour of $b$ and $a$ as function of $W$ is nearly parabolic with an opposite curvature. It is worthwhile recalling that the parameter $a$ is the absorption coefficient of the water vapour band within the range $930-950 \mathrm{~nm}$, weighted by both spectral curves of interference filter transmission and sensor responsivity, and that $b$ is dependent on the intensity of the band within the spectral interval covered by the sunsky radiometer filter centred at $940 \mathrm{~nm}$. The mutual correlation between $W$, its vertical distribution and the temperature vertical profile can affect parameter $a$ (because of the broadening of the absorption line) as well as $b$.

We observe that the lowest and highest $W$ classes have a similar behaviour. Such boundary classes, conversely to the other atmospheric situations, are characterized by a trapping of $W$ due to winter inversion (in the first one) and by the occurrence of convection (in the fourth one), which favours the development of a vertical structure having one well-mixed layer at the bottom and a rapid decrease upward.

In order to test such hypothesis using the available radiosonde vertical profiles, we introduced two indices to describe the $W$ vertical distribution and having different sensitivity to the shape of the distribution. One index $\left(P_{50}\right)$ is the pressure $P$ at which is found $50 \%$ of total $W$. The second index is the pressure $P$ weighted for the mixing ratio value $q,\left(P_{Q}\right)$ as in Eq. (8):

$P_{Q}=\frac{\sum_{z=1, N} P(z) q(z)}{\sum_{z=1, N} q(z)}(\mathrm{hPa})$, 
Table 2. Number of data points for each classes; optimal values of $a, b$ and $V_{0}$ for each water vapour class and their estimated errors; estimated uncertainties of $W_{P}$.

\begin{tabular}{|c|c|c|c|c|c|c|c|c|}
\hline $\begin{array}{l}\text { Classes } \\
(\mathrm{mm})\end{array}$ & $\begin{array}{r}\text { N. points } \\
\text { (SHM } \\
\text { GPS2) }\end{array}$ & $\begin{array}{r}a \\
\text { (SHM } \\
\text { GPS2) }\end{array}$ & $\begin{array}{r}b \\
\text { (SHM } \\
\text { GPS2) }\end{array}$ & $\begin{array}{r}V_{0} \times 10^{-4} \\
(\mathrm{SHM} \\
\text { GPS2) }\end{array}$ & $\begin{array}{r}\Delta a \\
(\mathrm{SHM} \\
\text { GPS2) }\end{array}$ & $\begin{array}{r}\Delta b \\
\text { (SHM } \\
\text { GPS2) }\end{array}$ & $\begin{array}{r}\Delta V_{0} \times 10^{-4} \\
(\mathrm{SHM} \\
\text { GPS2) }\end{array}$ & $\begin{array}{r}\Delta W_{P} \% \\
(\mathrm{SHM} \\
\text { GPS2) }\end{array}$ \\
\hline \multirow[t]{2}{*}{ [0-10] } & 601 & 0.218 & 0.52 & 2.49 & 0.027 & 0.02 & 0.02 & 3 \\
\hline & 728 & 0.138 & 0.63 & 2.21 & 0.012 & 0.02 & 0.02 & 5 \\
\hline \multirow[t]{2}{*}{ [10-20] } & 643 & 0.143 & 0.60 & 2.09 & 0.018 & 0.03 & 0.03 & 7 \\
\hline & 712 & 0.161 & 0.59 & 2.39 & 0.012 & 0.01 & 0.02 & 1 \\
\hline \multirow[t]{2}{*}{ [20-40] } & 977 & 0.166 & 0.60 & 2.39 & 0.020 & 0.02 & 0.04 & 11 \\
\hline & 1210 & 0.165 & 0.59 & 2.44 & 0.009 & 0.01 & 0.01 & 2 \\
\hline \multirow[t]{2}{*}{ [> 40] } & 476 & 0.142 & 0.62 & 2.34 & 0.020 & 0.02 & 0.03 & 1 \\
\hline & 811 & 0.125 & 0.64 & 2.17 & 0.008 & 0.01 & 0.01 & 1 \\
\hline $\begin{array}{l}\text { Fixed value } \\
\text { from simulation }\end{array}$ & & 0.141 & 0.626 & 2.33 & & & & \\
\hline
\end{tabular}

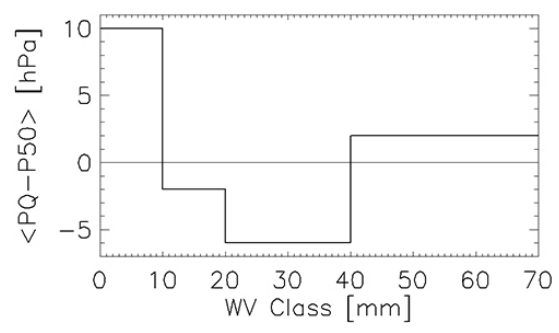

Fig. 6. $\left(P_{50}-P_{Q}\right)$ quantity versus water vapour, averaged over the four $W$ classes.

where $N$ is the number of vertical available measurement, taken below $100 \mathrm{hPa}$ with the threshold that there are at least 16 vertical measurements to obtain a good quality radiosonding.

The $P_{Q}$ index shows a greater sensitivity to the presence of well-mixed layers with respect to the $P_{50}$ index, being able to discriminate (the total amount of $W$ being equal) whether water vapour is distributed within one layer or homogeneously along the entire vertical. In the former case $P_{Q}$ assumes values lower than in the latter case. Consequently, the analysis of the difference $\left(P_{50}-P_{Q}\right)$ will assume higher values when the $W$ vertical structure will be characterized by one well-mixed layer at the bottom and a rapid decrease upward. In Fig. 6 the quantity $\left(P_{50}-P_{Q}\right)$, averaged over the same four $W$ classes analysed in this study, is shown. It is evident that in the first and fourth class the index has the same behaviour, as happens for $a$ and $b$ in Fig. 4, validating our hypothesis.

\section{Water vapour estimation}

Once the optimal parameters $(a, b)$ and $V_{0}$ are estimated for each of the selected water vapour classes, a calibration table of the site and of the instrument under study is constructed. $W_{P}$ can be instantaneously calculated as in Eq. (4) using this table, as soon as $V(940 \mathrm{~nm})$ and $\tau_{\mathrm{a}}(940 \mathrm{~nm})$ measurements are performed. To retrieve the water vapour content, an iterative procedure has been set up as follows: (i) for each $V$ $(940 \mathrm{~nm})$ and $\tau_{\mathrm{a}}(940 \mathrm{~nm})$ measurement, $W_{P}$ is calculated using the set of four parameters; (ii) each of the four $W_{P}$ values falls into one class of water vapour: when at least three of them converge within the same class, the pertinent parameters to be used for the current measurement are identified.

$W_{P}$ was calculated using the independent data sets from both GPS ( $\left.W_{P} / \mathrm{GPS} 2\right)$ and SHM ( $\left.W_{P} / \mathrm{SHM}\right)$ and the errors affecting the retrievals $\left(\Delta W_{P} \%\right)$ were estimated by a comparison against $W_{\text {GPS1 }}$. The calculated absolute median percentage difference (shown in Table 2 ) varies from $1 \%$ to $5 \%$ for $W_{P / \mathrm{GPS} 2}$ and from $1 \%$ to $11 \%$ for $W_{P / \mathrm{SHM}}$.

The comparison between $W_{P / \text { GPS2 }}$ and $W_{P / \text { SHM }}$ (Table 3 ), showed a very high total correlation (0.99), and a median percentage difference varying from $-0.4 \%$ (for the fourth class) up to $-9 \%$ (for the third class), although always within the error $\Delta W_{P / \mathrm{SHM}}$. A general underestimation by $W_{P / \mathrm{SHM}}$ is observed. The most unexpected result is the small difference between the two $W_{P}$ estimations in the first class, where conversely the retrieved $a, b$ parameters are very different. This topic will be discussed more deeply in Sect. 6 .

Before validating $W_{P}$ retrievals against MWR or RDS, we checked the goodness of these former water vapour evaluations with respect to GPS (specifically $W_{\mathrm{GPS} 2}$, being closest to Chiba University where the MWR is located), which, as already stated, is actually the methodology providing the highest quality estimation of $W$. Figures $7 \mathrm{a}$ and $\mathrm{b}$ show the 
Table 3. Correlation coefficients and median difference among $W_{P} / \mathrm{SHM}, W_{P / \mathrm{GPS} 2}, W_{S}$, and measurements taken by GPS, microwave radiometer and radiosondes.

\begin{tabular}{|c|c|c|c|c|c|c|c|c|}
\hline \multirow[b]{2}{*}{ Classes (mm) } & \multicolumn{4}{|c|}{$R^{2}\left(N_{\text {points }}\right)$} & \multicolumn{4}{|c|}{ median difference $(\mathrm{mm}) ;$ median $\%$ diff } \\
\hline & $\begin{array}{r}W_{P / \mathrm{SHM}}, W_{\mathrm{RDS}} \\
W_{P / \mathrm{GPS} 2}, W_{\mathrm{RDS}} \\
W_{\mathrm{SFIX}}, W_{\mathrm{RDS}}\end{array}$ & $\begin{array}{r}W_{P / \mathrm{SHM}}, W_{\mathrm{MWR}} \\
W_{P / \mathrm{GPS} 2}, W_{\mathrm{MWR}} \\
W_{\mathrm{SFIX}}, W_{\mathrm{MWR}}\end{array}$ & $\begin{array}{r}W_{P / \mathrm{SHM}}, W_{\mathrm{GPS} 2} \\
W_{\mathrm{SFIX}}, W_{\mathrm{GPS} 2}\end{array}$ & $\begin{array}{r}W_{P / \mathrm{SHM}}, W_{\mathrm{SFIX}} \\
W_{P / \mathrm{GPS} 2}, W_{\mathrm{SFIX}} \\
W_{P / \mathrm{SHM}}, W_{P / \mathrm{GPS} 2}\end{array}$ & $\begin{array}{r}W_{P} / \mathrm{SHM}-W_{\mathrm{RDS}} \\
W_{P / \mathrm{GPS} 2}-W_{\mathrm{RDS}} \\
W_{\mathrm{SFIX}}-W_{\mathrm{RDS}}\end{array}$ & $\begin{array}{r}W_{P / \mathrm{SHM}}-W_{\mathrm{MWR}} \\
W_{P} / \mathrm{GPS} 2-W_{\mathrm{MWR}} \\
W_{\mathrm{SFIX}}-W_{\mathrm{MWR}}\end{array}$ & $W_{P / \mathrm{SHM}}-W_{\mathrm{GPS} 2}$ & $\begin{array}{r}W_{\mathrm{SFIX}}-W_{P / \mathrm{GPS} 1} \\
W_{P / \mathrm{SHM}}-W_{P / \mathrm{GPs} 1}\end{array}$ \\
\hline$[0-10]$ & $\begin{array}{l}0.69(47) \\
0.64(44) \\
0.64(44)\end{array}$ & $\begin{array}{l}0.59(2477) \\
0.51(2182) \\
0.56(2201)\end{array}$ & $\begin{array}{l}0.81(2716) \\
0.84(2440)\end{array}$ & $\begin{array}{l}0.97(2716) \\
0.99(2421) \\
0.97(2716)\end{array}$ & $\begin{array}{r}-0.58 ;-9 \\
-0.60 ;-7 \\
0.03 ; 0.4\end{array}$ & $\begin{array}{r}-0.25 ;-3 \\
0.10 ; 2 \\
0.76 ; 11\end{array}$ & $0.16 ; 3$ & $\begin{array}{r}0.94 ; 15 \\
0.14 ; 3\end{array}$ \\
\hline [10-20] & $\begin{array}{l}0.87(20) \\
0.85(19) \\
0.86(23)\end{array}$ & $\begin{array}{l}0.72(2050) \\
0.79(1967) \\
0.85(2259)\end{array}$ & $\begin{array}{l}0.77(2026) \\
0.86(2236)\end{array}$ & $\begin{array}{l}0.93(2050) \\
0.99(1967) \\
0.96(2050)\end{array}$ & $\begin{array}{r}-0.25 ;-1 \\
-0.05 ;-0.3 \\
-0.04 ;-0.4\end{array}$ & $\begin{array}{l}-1.34 ;-8 \\
-0.15 ;-1 \\
-0.07 ;-1\end{array}$ & $-0.84 ;-5$ & $\begin{array}{r}0.22 ; 2 \\
-1.03 ; 7\end{array}$ \\
\hline [20-40] & $\begin{array}{l}0.85(15) \\
0.83(15) \\
0.84(17)\end{array}$ & $\begin{array}{l}0.90(1245) \\
0.94(1302) \\
0.94(1373)\end{array}$ & $\begin{array}{l}0.86(1225) \\
0.91(1349)\end{array}$ & $\begin{array}{l}0.97(1245) \\
0.99(1302) \\
0.99(1302)\end{array}$ & $\begin{array}{r}-2.87 ;-9 \\
0.28 ; 1 \\
-0.53 ;-2\end{array}$ & $\begin{array}{l}-2.89 ;-9 \\
-0.19 ;-1 \\
-0.80 ;-2\end{array}$ & $-2.79 ;-9$ & $\begin{array}{r}-1.21 ; 4 \\
-3.28 ;-11\end{array}$ \\
\hline [>40] & $\begin{array}{r}0.69(8) \\
0.40(10) \\
0.47(9)\end{array}$ & $\begin{array}{l}0.87(582) \\
0.81(676) \\
0.83(591)\end{array}$ & $\begin{array}{l}0.83(582) \\
0.79(591)\end{array}$ & $\begin{array}{l}0.99(582) \\
0.99(676) \\
0.99(582)\end{array}$ & $\begin{array}{r}-0.11 ;-0.2 \\
-0.21 ;-0.4 \\
-1.55 ;-3\end{array}$ & $\begin{array}{r}0.53 ; 1 \\
0.57 ; 1 \\
-1.04 ;-2\end{array}$ & $0.47 ; 1$ & $\begin{array}{r}-1.81 ; 4 \\
-0.37 ;-0.9\end{array}$ \\
\hline All the classes & $\begin{array}{l}0.96(79) \\
0.97(79) \\
0.97(79)\end{array}$ & $\begin{array}{l}0.97(5537) \\
0.99(5537) \\
0.99(5537)\end{array}$ & $\begin{array}{l}0.98(5752) \\
0.99(5752)\end{array}$ & $\begin{array}{l}0.99(5776) \\
0.99(5776) \\
0.99(5776)\end{array}$ & $\begin{array}{r}-0.65 ;-8 \\
-0.30 ; 2 \\
-0.04 ;-0.4\end{array}$ & $\begin{array}{r}-1.09 ;-7 \\
-0.01 ;-0.1 \\
-0.16 ;-1\end{array}$ & $-0.35 ;-3$ & $\begin{array}{r}0.32 ; 3 \\
-0.44 ;-3\end{array}$ \\
\hline
\end{tabular}

scatter plot of $W_{\mathrm{GPS} 2}$ versus $W_{\mathrm{RDS}}$ and $W_{\mathrm{MWR}}$, respectively. The disagreement with radiosonding varies from $1 \%$ to $10 \%$ (the higher value being for the first $W$ class) with a general overestimation from RDS. Conversely, the comparison with $W_{\mathrm{MWR}}$ highlights a bias with respect to $W_{\mathrm{GPS} 2}$, almost constant for all the classes, and expressed by the linear relationship $W_{\mathrm{GPS} 2}=0.99 W_{\mathrm{MWR}}+3.34$. We decided to correct MWR estimation by shifting $W_{\text {MWR }}$ values according to this formula. After the correction the disagreement between $W_{\mathrm{RDS}}$ and $W_{\mathrm{MWR}}$ was found to vary from $1 \%$ to $19 \%$ whereas the disagreement between $W_{\mathrm{GPS} 2}$ and $W_{\mathrm{MWR}}$ was found to be within $1 \%$ to $6 \%$, the higher value being for the first $W$ class.

The validation of the proposed methodology was performed by comparing $W_{P / \mathrm{SHM}}$ against the corrected $W_{\mathrm{MWR}}$, $W_{\mathrm{RDS}}$ and $W_{\mathrm{GPS} 2}$, whereas $W_{P / \mathrm{GPS} 2}$ was compared only against the former two. Simultaneous measurements within $\pm 15 \mathrm{~min}$ and $\pm 1 \mathrm{~h}$ respectively were selected. It must be taken into account that only $W_{\mathrm{RDS}}$ measurements taken at 09:00 local time can be compared with $W_{P}$ estimations. Scatter plots of $W_{P / \mathrm{GPS} 2}$ and $W_{P} / \mathrm{SHM}$ versus $W_{\mathrm{MWR}}, W_{\mathrm{RDS}}$ and $W_{\mathrm{GPS} 2}$ are shown in Fig. 7c-g and the corresponding correlation coefficients and median percentage differences are given in Table 3.

$W_{P / \text { GPS2 } 2}$ and $W_{P} /$ SHM were found to be very well correlated with both $W_{\mathrm{MWR}}, W_{\mathrm{RDS}}$ and $W_{\mathrm{GPS} 2}$ (total correlation varying from 0.97 to 0.99 ). The median difference between $W_{P / \text { GPS2 }}$ and $W_{\text {MWR }}$ showed a very good agreement always within the percentage error $\Delta W_{P}$. The same results are found for the comparison with $W_{\mathrm{RDS}}$, with the exception of the first class where a difference of $-7 \%$ was found, with a slight underestimation of $W_{P / \mathrm{GPS} 2}$ with respect to $W_{\mathrm{RDS}}(0.60 \mathrm{~mm})$.

The median difference between $W_{P} / \mathrm{SHM}$ and $W_{P} / \mathrm{GPS} 2$ showed a very good agreement always within $\Delta W_{P} / \mathrm{SHM}$. The comparison with $W_{\mathrm{MWR}}$ and $W_{\mathrm{RDS}}$ highlighted an
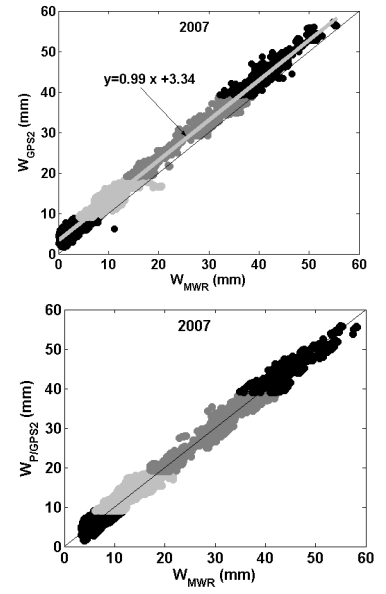

a)
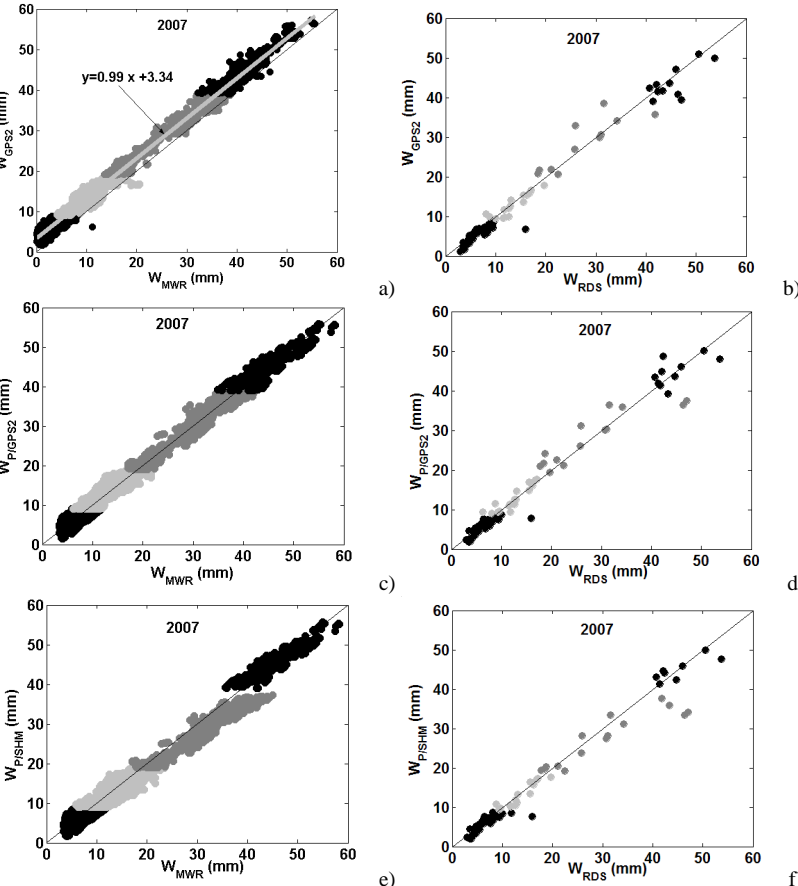

c)
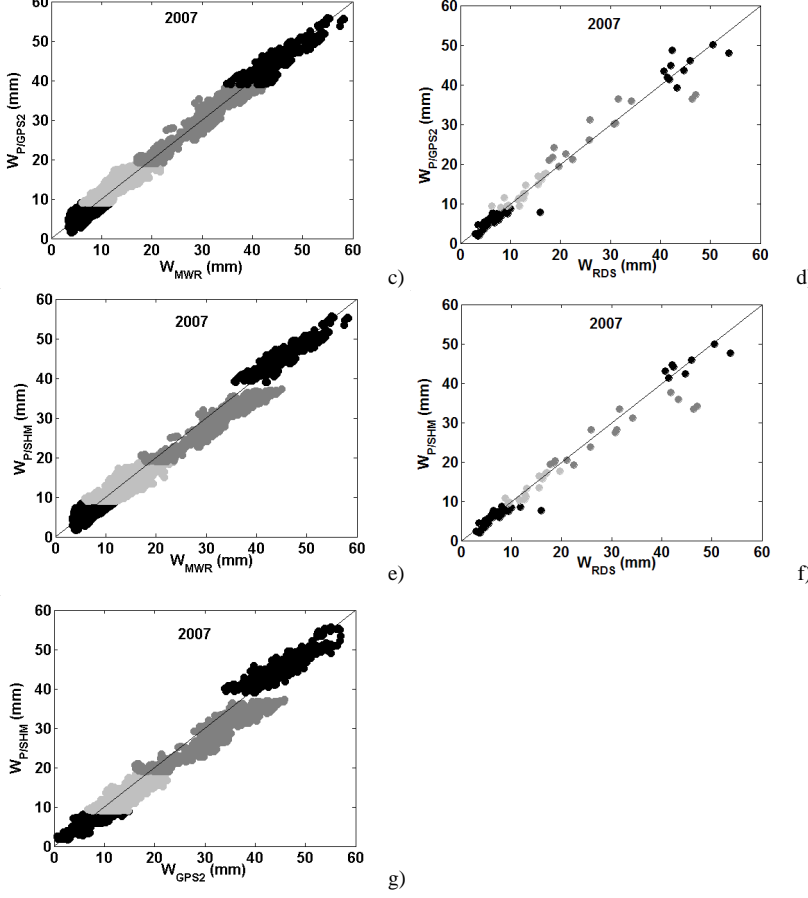

Fig. 7. Scatter plots of $W_{\mathrm{GPS} 2}$ versus $W_{\mathrm{RDS}}$ and $W_{\mathrm{MWR}}(\mathbf{a})$, (b) and of $W_{P} / \mathrm{GPS} 2$ and $W_{P} / \mathrm{SHM}$ versus $W_{\mathrm{MWR}}, W_{\mathrm{RDS}}$ and $W_{\mathrm{GPS} 2}$ (c)(g). Alternations of grey and black indicate the four water vapour classes. 
underestimation by $W_{P / \mathrm{SHM}}$ in the second $W$ class $(-1.34 \mathrm{~mm})$ and in the first $W$ class $(-0.50 \mathrm{~mm})$ respectively. It is worth noting that for the third class the largest disagreement was found $(-9 \%)$ showing an underestimation from $W_{P} / \mathrm{SHM}$ of about $3 \mathrm{~mm}$, but this class is also characterized by the greatest $\Delta W_{P}(11 \%)$.

In order to validate and verify the improvements brought by the principal assumption of the proposed methodology, that is the dependence of $a, b$ from water vapour amount, a simulation of the transmittance was performed using a radiative transfer code written by A. Uchiyama (unpublished data). The code calculates the atmospheric transmittance using a correlated $k$ distribution method with band width of $10 \mathrm{~nm}$, which is a good approximation for our study. The data base of correlated $k$ distribution was calculated based on the HITRAN data base using a line-by-line code. The code takes into account the curvature of the earth and the refraction of solar path, and does not include aerosol and cirrus clouds. The filter response function of the PREDE POM 02 was sampled; six original atmospheric models from McClatchey et al.'s (1972) (tropical, mid-latitude summer, midlatitude winter, subarctic summer, subarctic winter, US standard atmosphere 1962) and four modified profiles obtained by reducing the column water vapour of one tenth, were used to calculate the transmittance at 10 different hours in order to simulate a large range of path length. 100 pairs of $m W$ and simulated transmittance $\left(T=\mathrm{e}^{-a(m W)^{b}}\right)$ were obtained and used to calculate by a fitting procedure the following parameters: $a_{s}=0.141, b_{s}=0.626$ (Table 2). $V_{0}$ was calculated using the Type- 2 modified Langley applied to 5 days having a smoothed water vapour diurnal time pattern and daily average values covering the range between 5 and $35 \mathrm{~mm}$. Their mean value and standard deviation was performed to calculate $V_{0 s}=2.33 \times 10^{-4}(\mathrm{~mA})$ with an uncertainty of $3.5 \%$. $a_{s}, b_{s}$ and the mean $V_{0 s}$ value resulted to be comparable with values provided by the SHM methodology in the class having the highest water vapour content (Fig. 4). $a_{s}, b_{s}$ and $V_{0 s}$ were therefore used in Eq. (4) to estimate the columnar water vapour $W_{s}$.

The improvement resulting from the hypothesis of $a, b$ pairs dependent on $W$ with respect to the commonly used assumption of fixed $a, b$ values was evaluated by comparing

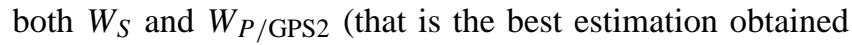
from the proposed methodology) against water vapour measured by GPS, being the most accurate retrieval of $W$. For this comparison $W_{\mathrm{GPS} 1}$ was chosen. Results (Fig. 8) show that in all the $W$ classes the agreement with $W_{\mathrm{GPS} 1}$ improves when the hypothesis of variable $a, b$ is assumed. This important outcome validates the goodness of the proposed methodology and highlights the capability of the presented methodology of monitoring the time change of $a$ and $b$ values, during years, on each site and then monitoring the instrumental condition.

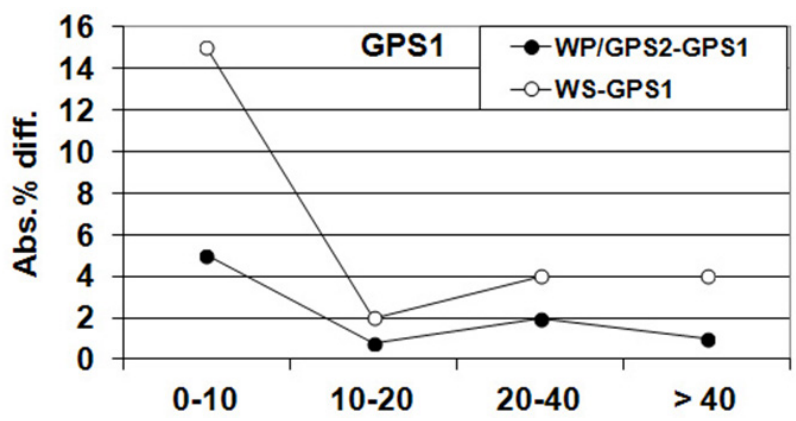

Fig. 8. Absolute median percentage difference between $W_{P / \text { GPS2 }}$ (black dots) and $W_{S}$ (white dots) versus $W_{\mathrm{GPS} 1}$.

\section{Discussion}

Looking at the water vapour dependence of the $a, b$ and $V_{0}$ parameters in Fig. 4 it is noticeable that the $b$ value for class [0-10] (and therefore also $a$ and $V_{0}$ ) from SHM are too different (in particular too low) with respect to the value retrieved using $W_{\text {GPS2 }}$ as independent data set. Nevertheless, $W_{P}$ SHM and $W_{P} /$ GPS2 for this class are in good agreement with a median difference of $3 \%$. To explain this effect, a study of the Jacobian elements from the derivative of Eq. (4) for the coefficients $a$ and $b$ has been performed. The analysis showed that the Jacobian for the $a$ coefficient is approximately three times the one for the $b$ coefficient, both being negative. Therefore any sets of $a$ and $b$ coefficients can introduce the same error in $W_{P}$ determination, if the difference between $b$ values is up to -3 times the difference between $a$ values. When this rule is respected, two pairs of $a$ and $b$ can provide exactly the same $W_{P}$. In our case the difference between optimal $b$ from SHM and $b$ from GPS data set is about -1.5 times the difference between the corresponding $a$ values, and this explains the good accordance between $W_{P} / \mathrm{SHM}$ and $W_{P} / \mathrm{GPS} 2$.

This analysis leads to the conclusion that there is a nonunique solution in the application of the SHM, unless we identify which vertical profiles of water vapour are able to provide such low $b$ values during winter time. The problem is likely linked to the nonlinearity of $y$ vs. $x$ during this season, and needs to be investigated in the future through simulation studies.

The application of SHM requires the determination of the coefficients explaining the linearity between precipitable water content and water vapour partial pressure. In the case under study we used an empirical formula for the relation between $W$ and $e_{0}$ obtained from a climatologic study typical of Japan, but this kind of study may not be always available for every site. One solution to this problem could be determining the proper coefficients in Eq. (7) by using already existing historical data sets of $W$ and $e_{0}$ measured in proximity of the site under study. If this is not possible, estimation 
of coefficients $c_{1}$ and $c_{2}$ can be found in the literature, from different daily or monthly data sets and from varying numbers of measurements and sites. With the aim of checking the error introduced if inappropriate coefficients are used for the estimation of $W_{\text {SHM }}$, the Choudhury (1996) formulation was considered. Choudhury examined a data set consisting of monthly mean values of $W$ and $e_{0}$ taken at 45 stations distributed over the entire planet, obtaining the average global values of $c_{1}=1.70$ and $c_{2}=-0.1$. The stations were far from water surfaces, with negligible influences due to evaporation and transport of humid air from marine regions, which are conditions not respected at all in the site under examination. $W_{\text {SHM }}$ calculated by the Choudhury formulation was used in Eqs. (2a) and (2b) to estimate the best $a, b$ and $V_{0}$ in each water vapour class, and water vapour from the sun-sky radiometer $\left(W_{P C}\right.$, where the subscript $c$ stands for discrimination from the $W_{P}$ retrieved using the Yamamoto formulation) was calculated using Eq. (4). Linear fitting of the scatter plot between $W_{P}$ and $W_{P C}$ (Fig. 9a) shows an intercept value of -1.22 and a slope value of 0.92 . This result indicates that even though the application of SHM can affect the validity of Eq. (2) when not completely appropriate parameters are used for estimating $W_{\mathrm{SHM}}$, this inaccuracy introduces an error mostly consisting of a bias, positive in our case. This is also confirmed by the scatter plot of the (normalized) time derivatives of the $W_{P}$ and $W_{P C}$ time series $\left(\frac{\Delta W_{P}}{\Delta t}\right.$ and $\frac{\Delta W_{P C}}{\Delta t}$ ) in Fig. 9b). In fact, the optimum agreement between the two series shows that $W_{P}$ and $W_{P C}$ have the same temporal behaviour. Therefore, in the case when the absolute calibration (in terms of $a, b, V_{0}$ ) is not correct, information from the relative values of $W_{P C}$ and its time derivatives can be extremely valuable, the temporal resolution of measurements being high (generally between 5 to $10 \mathrm{~min}$ ). However, it is strongly suggested not to use formulas of linearity between $W$ and $e_{0}$ obtained for sites with characteristics completely different from the place under study.

Before having columnar water vapour estimations, a new user installing a sun-sky radiometer for the first time must build a statistically significant data set for the proper calibration table of the site and the instrument under study showing the water vapour dependence of the optimal parameters $a, b$ and $V_{0}$. Time is needed to collect simultaneous measurement of direct solar irradiance and pressure, temperature and relative humidity (in the case when the SHM method is used) or other independent measurements provided that they cover the entire range of variability of columnar water vapour typical of the site under study. This gap could be filled at the beginning of operations by using the method based on the simulation of transmittance, and data can be later reprocessed once the calibration table is available.

An innovative application of the presented procedure could be the possibility of providing an estimation of water vapour scale height using $W_{P}$ and the water vapour obtained at the ground from pressure temperature and relative humidity measurements, provided for example from the installation
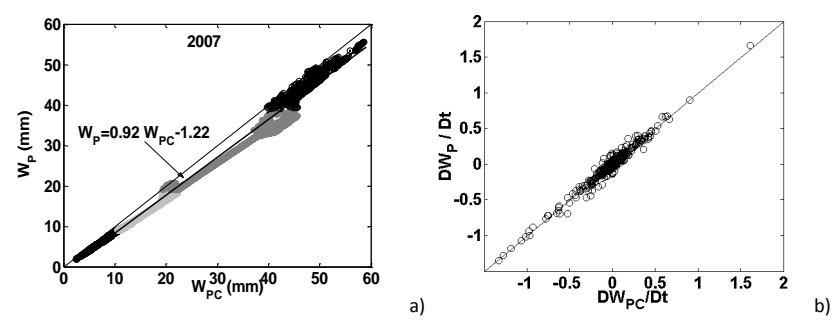

Fig. 9. Scatter plots of $W_{P}$ versus water vapour obtained using the Choudhury formulation, $W_{P C}$ (a) and their normalized time derivatives (b).

of sensors on the head of the PREDE sun-sky radiometer. In fact

$W_{P}=C \int W_{0} \mathrm{e}^{-\frac{z}{z_{0}}} \mathrm{~d} z$,

where $W_{0}$ is the water vapour density at the earth's surface, $z_{0}$ is the scale height $(\mathrm{km})$ and $C$ is a constant taking into account the unit of measurement conversion. By inverting Eq. (9) it is possible to determine $z_{0}$ and therefore provide a sort of vertical profile from an instrument that typically retrieves only columnar properties.

\section{Conclusions}

A new methodology for determining columnar water vapour from sun-sky radiometer measurements of direct solar irradiance at $940 \mathrm{~nm}$ has been introduced, based on the hypothesis that the calibration parameters characterizing the atmospheric transmittance at this wavelength are dependent on vertical profiles of temperature, air pressure and moisture occurring at each measurement site. To obtain calibration parameters from the proposed methodology, some seasonal independent measurements of water vapour taken over a large range of solar zenith angle, simultaneously with the sun-sky radiometer measurements, are needed. In the present paper we used two independent $W$ data sets: one estimated from GPS receivers and the other by the SHM, a cheap procedure, easy to implement, which is able to retrieve columnar $\mathrm{W}$ using measurements of surface temperature, pressure and relative humidity. Several aspects were developed with respect to the previous paper of Campanelli et al. (2010): the dependence of calibration parameter $(a, b)$ on columnar water vapour amount for an entire year data set; the estimation of $a$ and $b$ retrieval errors using a Monte Carlo method; the goodness and weakness of the SHM, examining in detail the accuracy, problems and utility of this methodology.

The behaviour of $a$ and $b$ parameters as function of $W$ was found to be nearly parabolic with an opposite curvature. The lowest and highest $W$ classes have similar behaviour probably because they are characterized by a $W$ vertical structure having a well-mixed layer at the bottom and a rapid decrease 
upward. This hypothesis was confirmed by the analysis of the available radiosonde measurements.

The $W_{P}$ obtained using GPS independent measurements, $W_{P / \mathrm{GPS} 2}$, was characterized by an error $\left(\Delta W_{P / \mathrm{GPS} 2}\right)$ varying from $1 \%$ up to $5 \%$ whereas $W_{P}$ from SHM, $W_{P / \mathrm{SHM}}$, showed an error $\left(\Delta W_{P / \mathrm{SHM}}\right)$ from $1 \%$ up to $11 \%$, depending on the $W$ classes.

The yearly time pattern of $W_{P}$ retrieved using both the two independent $W$ data sets was compared against simultaneous measurements taken by a microwave radiometer, MWR, radiosonde, RDS and GPS receivers, showing a total correlation varying from 0.97 up to 0.99 .

The accordance between $W_{P / \text { GPS2 }}$ and both MWR and RDS was found to be always within the error $\Delta W_{P / \mathrm{GPS} 2}$, with the exception of the first class for RDS where a slight underestimation by $W_{P / \text { GPS2 }}(0.6 \mathrm{~mm})$ was found. $W_{P} / \mathrm{SHM}$ showed a good agreement with GPS retrievals, always within the uncertainty $\Delta W_{P / \mathrm{SHM}}$. The comparison of $W_{P / \mathrm{SHM}}$ with respect to MWR highlighted an underestimation by the SHM in the second $W$ class $(-1.34 \mathrm{~mm})$, whereas comparison with respect to RDS showed again an underestimation by the SHM but in the first $W$ class $(-0.59 \mathrm{~mm})$.

The improvement in the $W_{P}$ estimation brought about by the assumption of $a, b$ dependent on $W$ was validated calculating water vapour $\left(W_{S}\right)$ by using the most common procedure adopted for example by the AERONET network, that consists in retrieving $a$ and $b$ parameters from a fitting procedure of simulated transmittance versus the product $m W$. $W_{P} /$ GPS2 and $W_{S}$ were compared against GPS retrievals and results showed a clear improvement using the data set obtained by the present methodology.

Despite the problems connected to the application of the SHM (independency of the $a, b$ and $V_{0}$ retrievals, determination of the coefficients explaining the linearity between $W$ and $\left.e_{0}\right) W_{P} /$ SHM was found to be in good agreement with the product from different instruments. In the case when the absolute calibration (in terms of $a, b, V_{0}$ ) proved not to be correct, information from $W_{P}$ relative values and time derivatives can be anyway extremely valuable.

We conclude that the simultaneous use of the simulation method and the proposed methodology can be one solution to make the water vapour product from the sun-sky radiometer healthy, because the latter method can monitor the instrumental condition through estimation of the time change of $a$ and $b$ values on each site. Moreover, the advantage of having simultaneous measurements of aerosol characteristics and water vapour columnar content with a high temporal resolution, and obtained by using only standard surface meteorological observation for calibrating the instrument, can be of great interest to the scientific community. The present procedure will in the future be applied to the instruments that are part of the SKYNET (Takamura and Nakajima, 2004; http://atmos.cr.chiba-u.ac.jp/) and ESR (Campanelli et al., 2012; http://www.euroskyrad.net/) networks on which web page the open source software will be released. It will also be tested against AERONET sun-sky radiometer measurements in order to compare the two methodologies.

Acknowledgements. This work is dedicated to the memory of our colleague and friend Vincenzo Malvestuto. He was always curious to deal with all scientific aspects, with spontaneous and generous intellectual honesty, artistically creating mathematical and statistical methodologies for explaining measurements. He gave a fundamental contribution to this work, developing with passion and enthusiasm the Monte Carlo approach. He passed away before this work was finished, leaving us with a deep sense of emptiness.

We thank Yoshinori Shoji of the Meteorological Research Institute, Ibaraki, Japan, for providing GPS data.

V. Estélles thanks the Spanish Ministry of Science and Innovation (MICINN) for the research contract under the Juan de la Cierva programme (JCI-2009-04455).

Edited by: A. Macke

\section{References}

Alexandrov, M. D., Schmid, B., Turner, D. D., Cairns, B., Oinas, V., Lacis, A. A., Gutman, S. I., Westwater, E. R., Smirnov, A., and Eilers, J.: Columnar water vapour retrievals from multifilter rotating shadowband radiometer data, J. Geophys. Res., 114, D02306, doi:10.1029/2008JD010543, 2009.

Bevis, M., Businger, S., Herring, T., Rocken, C., Anthes, R. A., and Ware, R. H.: GPS meteorology: Remote sensing of the atmospheric water vapor using the global positioning system, J. Geophys. Res., 97, 15787-15801, 1992.

Bruegge, C. J., Conel, J. E., Green, R. O., Margolis, J. S., Holm, R. G., and Toon, G.: Water vapor column abundances retrievals during FIFE, J. Geophys. Res., 97, 18759-18768, 1992.

Campanelli, M., Lupi, A., Nakajima, T., Malvestuto, V., Tomasi, C., and Estelles, V.: Summertime columnar content of atmospheric water vapour from ground-based Sun-sky radiometer measurements through a new in situ procedure, J. Geophys. Res., 115, D19304, doi:10.1029/2009JD013211, 2010.

Campanelli, M., Estelles, V., Smyth, T., Tomasi, C., MartìnezLozano, M. P., Claxton, B., Muller, P., Pappalardo, G., Pietruczuk, A., Shanklin, J., Colwell, S., Wrench, C., Lupi, A., Mazzola, M., Lanconelli, C., Vitale, V., Congeduti, F., Dionisi, D., and Cacciani, M.: Monitoring of Eyjafjallajoekull volcanic aerosol by the new European SkyRad users(ESR) sun-sky radiometer network, Atmos. Environ., 48, 33-45, 2012.

Choudhury, B. J.: Comparison of two models relating precipitable water to surface humidity using globally distributed radiosonde data over land surfaces, Int. J. Climatol., 16, 663-675, 1996.

Durre, I., Vose, R. S., and Wuertz David, B.: Overview of the Integrated Global Radiosonde Archive, J. Climate, 19, 53-68, 2006.

Halthore, R. N., Eck, T. F., Holben, B. N., and Markham, B. L.: Sun photometric measurements of atmospheric water vapor column abundance in the $940 \mathrm{~nm}$ band, J. Geophys. Res., 102, 43434352, doi:10.1029/96JD03247, 1997.

Hay, J. E.: Precipitable water over Canada: Part I. Computation, Atmosphere, 8, 128-143, 1970.

Holben, B. N., Eck, T. I., Slutsker, I., Tanré, D., Buis, J. P., Setzer, A., Vermote, E., Reagan, J. A., Kaufman, Y. J., Nakajima, 
T., Lavenu, F., Jankowiak, I., and Smirnov, A.: AERONET - A federated instrument network and data archive for aerosol characterization, Remote Sens. Environ., 66, 1-16, 1998.

Kasten, F. and Young, A. T.: Revised optical air mass tables and approximation formula, Appl. Optics, 28, 4735-4738, 1989.

Kneizys, F. X., Shettle, E. P., Gallery, W. O., Chetwynd, J. H., Abreu, L. W., Selby, J. E. A., Clough, S. A., and Fenn, R. W.: Atmospheric Transmittance/Radiance: Computer Code LOWTRAN 6, AFGL-TR-83-0187, Environmental Research Papers No. 846, 1983.

Liu, W. T.: Statistical relation between monthly mean precipitable water and surface level humidity over global oceans, Mon. Weather Rev., 114, 1591-1602, 1986.

McClatchey, R. A., Fenn, R. W., Selby, J. E. A., Volz, F. E., and Garing, J. S.: Optical Properties of the Atmo sphere, 3rd Edn., AFCRL 72-0497, AD 753075, 1972.

Ortiz de Galisteo, J. P., Cachorro, V., Toledano, C., Torres, B., Laulainen, N., Bennouna, Y., and de Frutos, A. M.: Diurnal cycle of precipitable water vapor over Spain, Q. J. Roy. Meteorol. Soc., 137, 948-958, doi:10.1002/qj.811, 2011.

Schmid, B., Michalsky, J. J., Slater, D. W., Barnard, J. C., Halthore, R. N., Liljegren, J. C., Holben, B. N., Eck, T. F., Livingston, J. M., Russell, P. B., Ingold, T., and Slutsker, I.: Comparison of columnar water vapor measurements from solar transmittance methods, Appl. Optics, 40, 1886-1896, 2001.
Shoji, Y.: Retrieval of Water Vapor Inhomogeneity using the Japanese Nationwide GPS Array and its Potential for Prediction of Convective Precipitation, J. Meteorol. Soc. Jpn., 91, 43-62, 2013.

Smirnov, A., Holben, B. N., Lyapustin, A., Slutsker, I., and Eck, T. F.: AERONET processing algorithms refinement, paper presented at AERONET Workshop, AERONET, PHOTON, El Arenosillo, Spain, 10-14 May, 2004.

Takamura, T. and Nakajima, T.: Overview of SKYNET and its activities, Opt. Pura Apl., 37, 3303-3308, 2004.

Tuller, S. E.: The relationship between precipitable water content and surface humidity in New Zealand, Arch. Meteorol. Geophys. Bioklimatol. Ser. A, 26, 197-212, 1977.

Yamamoto, G., Tanaka, M., and Arao, K.: Secular variation of atmospheric turbidity over Japan, J. Meteorol. Soc. Jpn., 49, 859-865, 1971.

World Meteorological Organization: Algorithms for Automatic Aerological Soundings (A. H. Huper), Instruments and Observing Methods Report No. 21, WMO-TD-No. 175, Geneva, 1986.

World Meteorological Organization: Manual on Codes International Codes VOLUME I.1 Part A - Alphanumeric Codes, WMONo. 306., Paragraph 35.3.1.3., 1995. 